\title{
7. As Grandes Epidemias da História
}

\author{
Joffre Marcondes de Rezende
}

REZENDE, J. M. As Grandes Epidemias da História. In: À sombra do plátano: crônicas de história da medicina [online]. São Paulo: Editora Unifesp, 2009, pp. 73-82. História da Medicina series, vol. 2. ISBN 978-85-61673-63-5. https://doi.org/10.7476/9788561673635.0008.

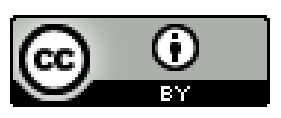

All the contents of this work, except where otherwise noted, is licensed under a Creative Commons Attribution 4.0 International license.

Todo o conteúdo deste trabalho, exceto quando houver ressalva, é publicado sob a licença Creative Commons Atribição 4.0.

Todo el contenido de esta obra, excepto donde se indique lo contrario, está bajo licencia de la licencia Creative Commons Reconocimento 4.0. 


\section{As Grandes Epidemias da História}

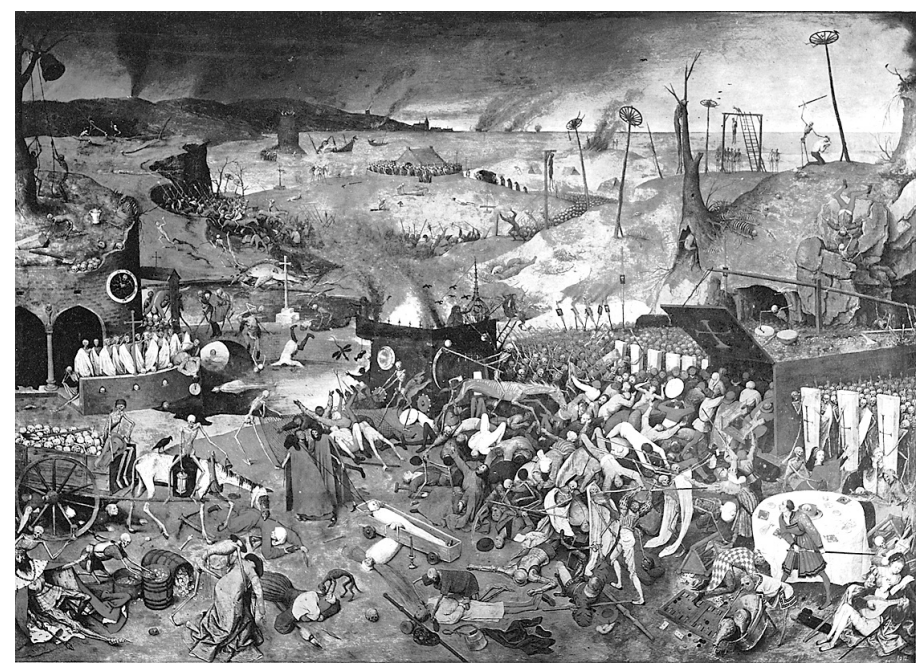

O Triunfo da Morte, de Pieter Bruegel (I 562), inspirado na peste negra do século XIV.

$\mathrm{E}$

m virtude das condições sanitárias das cidades e do desconhecimento da etiologia das doenças infecciosas, grandes epidemias assolaram as nações no passado, dizimando suas populações, limitando o crescimento demográfico, e mudando, muitas vezes, o curso da história.

Tais epidemias foram genericamente rotuladas de peste, embora muitas delas não tenham sido causadas pelo bacilo da peste (Yersinia pestis) e fossem, provavelmente, epidemias de varíola, tifo exantemático, cólera, malária ou febre tifoide.

Possivelmente a primeira notícia sobre a peste bubônica seja a narrativa que se encontra na Bíblia sobre a praga que acometeu os filisteus. Estes tomaram dos hebreus a arca do Senhor e foram castigados: "A mão do Senhor veio contra aquela cidade, com uma grande vexação; pois feriu aos homens daquela cidade, desde o pequeno até ao grande e tinham hemorroidas nas partes secretas" (Samuel I:6.9). Decidiram, então, devolver a arca, com a oferta de cinco ratos de ouro e cinco hemorroidas de ouro: "Fazei, pois, umas imagens das vossas hemorroidas e as imagens dos vossos ratos, que 
andam destruindo a terra, e dai glória ao Deus de Israel" (Samuel ı:6,5). E os hebreus também foram vitimados pela peste após receberem a arca de volta: "E feriu o Senhor os homens de Bete-Semes, porquanto olharam para dentro da arca do Senhor, até ferir do povo cinquenta mil e setenta homens; então o povo se entristeceu, porquanto o Senhor fizera grande estrago entre o povo" (Samuel I:6, I9, A Bíblia Sagrada, I98 I, pp. 287-289).

É digno de nota o fato de que os povos daquela época já haviam estabelecido ligação entre os ratos e a peste; do contrário, a oferta de expiação não seria constituída de hemorroidas (bubões) e de ratos. Aliás, esta ligação já havia sido referida em textos antigos da medicina hindu - Susruta, ı००० d.C. (Castiglioni, I947, p. I04).

A referência a hemorroidas teria sido um equívoco de tradução, como muito bem argumentou Pitanga Santos em seu artigo "O termo hemorroidas na Bíblia" (Santos, I967). A palavra Epholim do texto original hebraico tem o sentido de inchação, tumefação, e poderia referir-se a gânglios enfartados (bubões na região inguinal) e não a uma afecção benigna como as hemorroidas. Os gânglios inflamados ou bubões, que caracterizam a peste é que lhe valeram o nome de peste bubônica.

Em edições mais recentes da Bíblia, os seus organizadores tiveram o bom senso de trocar "hemorroidas" por "tumores" (A Bíblia Sagrada, I993, pp. 302-303).

As maiores epidemias registradas pelos historiadores foram a peste de Atenas, a peste de Siracusa, a peste Antonina, a peste do século III, a peste Justiniana e a Peste Negra do século XIv. No interregno entre as epidemias citadas, outras de menor vulto foram registradas.

\section{Peste de Atenas}

A peste de Atenas ocorreu em 428 a.C. e foi narrada por Tucídides, em seu livro História da Guerra do Peloponeso. O relato que deixou da epidemia é tão rico de informações que merece ser conhecido no texto original. Vejamos algumas passagens:

No começo do verão, os peloponesos e seus aliados invadiram o território da Ática. Firmaram seu campo e dominaram o país. Poucos dias depois, sobreveio 
aos atenienses uma terrível epidemia, a qual atacou primeiro a cidade de Lemnos e outros lugares. Jamais se vira em parte alguma açoite semelhante e vítimas tão numerosas; os médicos nada podiam fazer, pois de princípio desconheciam a natureza da enfermidade e além disso foram os primeiros a ter contato com os doentes e morreram em primeiro lugar. A ciência humana mostrou-se incapaz; em vão se elevavam orações nos templos e se dirigiam preces aos oráculos. Finalmente, tudo foi renunciado ante a força da epidemia.

[...] Em geral, o indivíduo no gozo de perfeita saúde via-se subitamente presa dos seguintes sintomas: sentia em primeiro lugar violenta dor de cabeça; os olhos ficavam vermelhos e inflamados; a língua e a faringe assumiam aspecto sanguinolento; a respiração tornava-se irregular e o hálito fétido. Seguiam-se espirros e rouquidão. Pouco depois a dor se localizava no peito, acompanhada de tosse violenta; quando atingia o estômago, provocava náuseas e vômitos com regurgitação de bile. Quase todos os doentes eram acometidos por crises de soluços e convulsões de intensidade variável de um caso a outro. A pele não se mostrava muito quente ao tato nem também lívida, mas avermelhada e cheia de erupções com o formato de pequenas empolas (pústulas) e feridas. O calor intenso era tão pronunciado que o contato da roupa se tornava intolerável. Os doentes ficavam despidos e somente desejavam atirar-se na água fria, o que muitos faziam. [...] A maior parte morria ao cabo de sete a nove dias consumida pelo fogo interior. Nos que ultrapassavam aquele termo, o mal descia aos intestinos, provocando ulcerações acompanhadas de diarreia rebelde que os levava à morte por debilidade.

[...] A enfermidade desconhecida castigava com tal violência que desconcertava a natureza humana. Os pássaros e os animais carnívoros não tocavam nos cadáveres apesar da infinidade deles que ficavam insepultos. Se algum os tocava caía morto.

[...] Nenhum temperamento, robusto ou débil, resistiu à enfermidade. Todos adoeciam, qualquer que fosse o regime adotado. $\mathrm{O}$ mais grave era o desespero que se apossava da pessoa ao sentir-se atacado: imediatamente perdia a esperança e, em lugar de resistir, entregava-se inteiramente. Contaminavam-se mutuamente e morriam como rebanhos (Tucídides, apud Lopes, I969, pp. I6I-I62).

As consequências da peste foram desastrosas para Atenas. Uma das vítimas da epidemia foi Péricles, o grande estadista, sob cujo governo a civilização grega atingiu o seu apogeu. 
Muito se tem discutido sobre a verdadeira natureza desta epidemia de Atenas (Sournia e Ruffie, I964, p. 79). A doença que mais se aproxima do quadro clínico descrito por Tucídides é o tifo exantemático; todavia, investigações recentes, utilizando técnicas avançadas de biologia molecular, sugerem tratar-se de febre tifoide. Papagrigorakis e col., em 2006, examinando a polpa dentária de esqueletos exumados de um antigo cemitério de Atenas da época da epidemia, detectaram, pela técnica de amplificação do DNA, a sequência genômica da Salmonella enterica serovar typhi, tendo sido negativas as pesquisas para os agentes da peste, tifo, antraz, tuberculose, varíola e bartonelose (Papagrigorakis et al., 2006).

\section{Peste de Siracusa}

Ocorreu no ano 396 a.C, quando o exército cartaginês sitiou Siracusa, na Itália. A doença surgiu entre os soldados, espalhando-se rapidamente entre eles, e dizimou o exército. Manifestava-se inicialmente com sintomas respiratórios, febre, tumefação do pescoço, dores nas costas. A seguir sobrevinham disenteria e erupção pustulosa em toda a superfície do corpo e, por vezes, delírio. Os soldados morriam ao fim do quarto ao sexto dia, com delírio e sofrimentos atrozes. O Império Romano foi o grande beneficiário dessa epidemia, vencendo facilmente os invasores (Lopes, I969, pp. I63-I64).

\section{Peste Antonina}

Assim chamada por ter surgido no século II d.C, quando o imperador Marco Aurélio, da linhagem dos Antoninos, dirigia o Império Romano. Causou grande devastação à cidade de Roma em I 66 d.C., estendeu-se por toda a Itália e, após um declínio temporário, recrudesceu em I 89 d.C. (Cartwright, I99I, p. I3). Foi contemporânea de Galeno, que assim descreveu os sintomas apresentados pelos doentes:

Ardor inflamatório nos olhos; vermelhidão sui generis da cavidade bucal e da língua; aversão pelos alimentos; sede inextinguível; temperatura exterior normal, contrastando com a sensação de abrasamento interior; pele avermelhada e úmida; tosse violenta e rouquidão; sinais de flegmasia laringobrônquica; fetidez do hálito; 
erupção geral de pústulas, seguida de ulcerações; inflamação da mucosa intestinal; vômitos de matérias biliosas; diarreia da mesma natureza, esgotando as forças; gangrenas parciais e separação espontânea dos órgãos mortificados; perturbações variadas das faculdades intelectuais; delírio tranquilo ou furioso e término funesto do sétimo ao nono dia (Lopes, op. cit.).

Vê-se que há certa semelhança do quadro clínico com o da peste de Atenas. Uma das vítimas da peste Antonina foi o próprio imperador, Marco Aurélio.

\section{A Peste do Século III}

Oriunda do Egito, rapidamente se espalhou à Grécia, norte da África e Itália nos anos de 25 I a 266 d.C., devastando o Império Romano. São Cipriano, bispo de Cartago, deixou a seguinte descrição da doença:

Iniciava-se por um fluxo de ventre que esgotava as forças. Os doentes queixavam-se de intolerável calor interno. Logo se declarava angina dolorosa; vômitos se acompanhavam de dores nas entranhas; os olhos injetados de sangue. Em muitos doentes, os pés ou outras partes atingidas pela gangrena, destacavam-se espontaneamente. Alquebrados, os infelizes eram tomados de um estado de fraqueza que lhes tornava a marcha vacilante. Uns perdiam a audição, e outros a visão. Em Roma e em certas cidades da Grécia, morriam até cinco mil pessoas por dia (Lopes, op. cit., p. I65).

\section{Peste Justiniana}

A peste justiniana foi assim chamada por ter-se iniciado no Império bizantino, ao tempo do imperador Justiniano, no ano de 542 d.C. Espalhou-se pelos países asiáticos e europeus, porém não teve a importância da grande epidemia do século XIV. Ao atingir Constantinopla, capital do Império (hoje Istambul), no ano de 542, chegou a causar cerca de dez mil mortes por dia. O pouco que se sabe sobre esta peste se deve ao relato de Procópio, um arquivista do Império:

Subitamente, os doentes apresentam febre ligeira; passado um dia ou mais surge um bubão em ambas a regiões, inguinal e axilar, ou em outra parte do cor- 
po. [...] A partir daí há diferenças individuais; alguns entram em coma, outros em delírio. [...] Alguns morrem logo, outros depois de muitos dias; e os corpos de alguns mostram bolhas negras do tamanho de uma lentilha [...] e muitos morrem vomitando sangue (Zinsser, I996, pp. I46-I47).

Este relato de Procópio sugere tratar-se de epidemia causada pelo bacilo Yersinia pestis.

\section{Peste Negra do Século XIV}

Esta foi a maior, a mais trágica epidemia que a história registra, tendo produzido um morticínio sem paralelo. Foi chamada Peste Negra pelas manchas escuras que apareciam na pele dos enfermos. Como em outras epidemias, teve início na Ásia Central, espalhando-se por via terrestre e marítima em todas as direções. Em I334 causou cinco milhões de mortes na Mongólia e no norte da China. Houve grande mortandade na Mesopotâmia e na Síria, cujas estradas ficaram juncadas de cadáveres dos que fugiam das cidades. No Cairo os mortos eram atirados em valas comuns e em Alexandria os cadáveres ficaram insepultos. Calcula-se em 24 milhões o número de mortos nos países do Oriente (Lopes, op. cit, p. I72).

Em I 347 a epidemia alcançou a Crimeia, o arquipélago grego e a Sicília. Em I 348 embarcações genovesas procedentes da Crimeia aportaram em Marselha, no sul da França, ali disseminando a doença. Em um ano, a maior parte da população de Marselha foi dizimada pela peste.

Em I349 a peste chegou ao centro e ao norte da Itália e dali se estendeu por toda a Europa. Em sua caminhada devastadora, semeou a desolação e a morte nos campos e nas cidades. Povoados inteiros se transformaram em cemitérios. Calcula-se que a Europa tenha perdido pelo menos um terço de sua população.

Esta epidemia inspirou o livro Decamerão, de Giovanni Bocaccio, que viveu de I 3 I 3 a I 375 . As cenas que descreve no prólogo do livro se passam na cidade de Florença, na Itália. Eis alguns trechos: "A peste, atirada sobre os homens por justa cólera divina e para nossa exemplificação, tivera início nas regiões orientais. Incansável, fora de um lugar para outro, e estendera-se 
de forma miserável para o Ocidente. [...] Nenhuma prevenção foi válida, nem valeu a pena qualquer providência dos homens".

Assim descreve Bocaccio os sintomas:

Apareciam, no começo, tanto em homens como nas mulheres, ou na virilha ou nas axilas, algumas inchações. Algumas destas cresciam como maçãs, outras como um ovo; cresciam umas mais, outras menos; chamava-as o povo de bubões. Em seguida o aspecto da doença começou a alterar-se; começou a colocar manchas de cor negra ou lívidas nos enfermos. Tais manchas estavam nos braços, nas coxas e em outros lugares do corpo. Em algumas pessoas as manchas apareciam grandes e esparsas; em outras eram pequenas e abundantes. E, do mesmo modo como, a princípio, o bubão fora e ainda era indício inevitável de morte, também as manchas passaram a ser mortais.

Retrata, a seguir, a situação de caos que se instalou na cidade:

Entre tanta aflição e tanta miséria de nossa cidade, a autoridade das leis, quer divinas quer humanas desmoronara e dissolvera-se. Ministros e executores das leis, tanto quanto outros homens, todos estavam mortos, ou doentes, ou haviam perdido os seus familiares e assim não podiam exercer nenhuma função. Em consequência de tal situação permitia-se a todos fazer aquilo que melhor lhes aprouvesse.

Uma das maiores dificuldades era dar sepultura aos mortos: "Para dar sepultura à grande quantidade de corpos já não era suficiente a terra sagrada junto às igrejas; por isso passaram-se a edificar igrejas nos cemitérios; punham-se nessas igrejas, às centenas, os cadáveres que iam chegando; e eles eram empilhados como as mercadorias nos navios" (Boccaccio, I979, pp. II-I6).

Em Avignon, na França, vivia Guy de Chauliac, o mais famoso cirurgião dessa época, médico do papa Clemente vi. Chauliac sobreviveu à peste e deixou o seguinte relato:

A grande mortandade teve início em Avignon em janeiro de I348. A epidemia se apresentou de duas maneiras. Nos primeiros dois meses manifestava-se com 
febre e expectoração sanguinolenta e os doentes morriam em três dias; decorrido esse tempo manifestou-se com febre contínua e inchação nas axilas e nas virilhas e os doentes morriam em cinco dias. Era tão contagiosa que se propagava rapidamente de uma pessoa a outra; o pai não ia ver seu filho nem o filho a seu pai; a caridade desaparecera por completo.

E continua: "Não se sabia qual a causa desta grande mortandade. Em alguns lugares pensava-se que os judeus haviam envenenado o mundo e por isso os mataram" (Castiglioni, op. cit., p. 420).

Durante a epidemia, o povo, desesperado, procurava uma explicação para a calamidade. Para alguns tratava-se de castigo divino, punição dos pecados, aproximação do Apocalipse. Para outros, os culpados seriam os judeus, os quais foram perseguidos e trucidados. Somente em Borgonha, na França, foram mortos cerca de cinquenta mil deles.

Atribuía-se, também, a disseminação da peste a pessoas que estariam contaminando as portas, bancos, paredes, com unguento pestífero. Muitos suspeitos foram queimados vivos ou enforcados. Em Koenisberg, na Alemanha, uma criada que havia transmitido a peste a seus patrões foi enforcada depois de morta e a seguir queimada. Na Itália, o conde que governava a Calábria decretou que todo pestoso fosse conduzido ao campo para ali morrer ou sarar, e ainda confiscou os bens dos que haviam adquirido a peste.

No meio de tanto desespero e irracionalidade, houve alguns episódios edificantes. Muitos médicos se dispuseram a atender os pestosos com risco da própria vida. Adotavam para isso roupas e máscaras especiais. Alguns dentre eles evitavam aproximar-se dos enfermos. Prescreviam à distância e lancetavam os bubões com facas de até $\mathrm{I}, 80 \mathrm{~m}$ de comprimento. Frades capuchinhos e jesuítas cuidaram dos pestosos em Marselha, correndo todos os riscos. Foi fundada a Confraria dos Loucos, que invocava a proteção de São Sebastião para combater o medo da morte. São Roque foi escolhido o padroeiro dos pestosos. Tratava-se de um jovem que havia adquirido a peste em Roma e havia se retirado para um bosque para morrer. Foi alimentado por um cão, que lhe levava pedaços de pão e conseguiu recuperar-se.

As consequências sociais, demográficas, econômicas, culturais e religiosas dessa grande calamidade que se abateu sobre os povos da Ásia e da Europa, foram imensas. As cidades e os campos ficaram despovoados; 
famílias inteiras se extinguiram; casas e propriedades rurais ficaram vazias e abandonadas, sem herdeiros legais; a produção agrícola e industrial reduziu-se enormemente; houve escassez de alimentos e de bens de consumo; a nobreza se empobreceu; reduziram-se os efetivos militares e houve ascensão da burguesia que explorava o comércio. O poder da Igreja se enfraqueceu com a redução numérica do clero e houve sensíveis mudanças nos costumes e no comportamento das pessoas (Major, I954, p. 34I).

A Peste Negra foi a maior, mas não a última das epidemias. A doença perseverou sob a forma endêmica por muitos anos e outras epidemias menores, localizadas, foram registradas nos séculos seguintes. Citam-se como surtos mais importantes a peste de Milão, Brescia e Veneza no século Xvi; a peste de Nápoles em I656; a peste de Londres em I655 (setenta mil mortes); a de Viena em I7I 3 e a de Marselha em I720, que matou metade de sua população.

Entre I 894 e I9I 2 houve uma outra pandemia que teve início na Índia (onze milhões de mortes), estendendo-se à China, de onde trasladou-se para a costa do Pacífico, nos Estados Unidos. No Brasil, a peste entrou pelo porto de Santos em I 899 e propagou-se a outras cidades litorâneas. A partir de I 906 foi banida dos centros urbanos, persistindo como enzootia em pequenos focos endêmicos residuais na zona rural.

O terrível flagelo da peste inspirou a imaginação criativa de pintores famosos. Os quadros mais notáveis são: A Peste em Atenas, do pintor belga Michael Sweerts (1624-I664), A Peste em Nápoles, de Domenico Gargiulo (I6I 2-I679), O Triunfo da Morte, do pintor belga Pieter Bruegel, o Velho ( 5 I O-I 569 ), e São Roque, de Bartolomeo Mantegna (I 45 O-I 523 ). Inspirou igualmente a Albert Camus, prêmio Nobel de Literatura, a escrever uma de suas obras mais conhecidas: A Peste.

No Novo Continente as pestes mais importantes foram as de varíola, trazidas pelos colonizadores espanhóis e portugueses, que dizimaram as populações indígenas, e a de febre amarela, autóctone da América Central, que atingiu os membros da expedição de Cristóvão Colombo e se espalhou para outros países do continente, inclusive o Brasil. Finalmente cabe mencionar a pandemia de gripe, chamada gripe espanhola, oriunda da Europa em I91 8, após a Primeira Guerra Mundial, com cerca de vinte milhões de vítimas (Liu, I983, p. 323 ). 


\section{Referências Bibliográficas}

A Bíblia Sagrada. Trad. de João Ferreira de Almeida. $50^{\mathrm{a}}$ impressão, Rio de Janeiro, Imprensa Bíblica Brasileira, I98 I.

. Trad. de João Ferreira de Almeida. $4^{\text {a }}$ edição revista e atualizada no Brasil,

Milwaukee, Spanish Pulications Inc., I993.

Bocaccio, G. Decamerão. São Paulo, Victor Civita, I979

Cartwrigt, F. F. Disease and History. New York, Dorse Press, I99I.

Castiglioni, A. História da Medicina. São Paulo, Cia. Editora Nacional, 1947.

Liu, C. "Influenza”. In Hoeprich, P.D. (ed.). Infectious Diseases. Philadelphia, Harper \& Row Publ., I983.

Lopes, O. C. A Medicina no Tempo. São Paulo, Edusp/Melhoramentos, I969.

Major, R. H. A History of Medicine. Oxford, Blackwell Scientific Publications, I954.

Papagrigorakis, M. I.; Yapijakis, C.; Synodinos, P. N. \& Baziotopoulou-Valani,

E. "DNA examination of ancient dental pulp incriminates typhoid fever as a proba-

ble cause of the Plague of Athens”. International Journal of Infectious Diseases Io, pp. 334-336, 2006.

SAntos, P. "O termo hemorróidas na Bíblia”. Jornal Brasileiro de Medicina I 2, pp. 5 I I5 I3, I967.

Sournia, J. C. \& Ruffie, J. As Epidemias na História do Homem. Lisboa, Edições 70, I964.

Ujvari, S. C. A História e suas Epidemias. Rio de Janeiro, Senac Rio Editora, 2003.

Zinsser, H. Rats, Lice and History. New York, Black Dog \& Leventhal Publ, I996. 